\title{
Mobile paste backfill systems - a decade of work
}

\author{
S Longo Golder Associates Ltd., Canada \\ A Quintero Golder Associates Ltd., Canada \\ D Kennard Golder Associates Ltd., Canada
}

\section{Introduction}

Mobile paste backfill applications are becoming more and more common as orphaned and abandoned mines are becoming challenges or even impediments to urban or recreational development. In addition, the public risk and safety issues associated with these orphaned sites are bringing remediation programs to the forefront. These sites are left in the hands of local, regional and federal governments to deal with, and they typically lack the resources from a financial and technical perspective to effectively reduce the risks these sites pose. The technical challenges of early 20th century mine plans, no current underground access, logistics and proximity to local communities associated with these orphaned sites, makes mobile paste backfill a viable option. This particular application of paste technology has not, to date, been widely utilised but is a growing area of need. This paper will discuss two case studies from the past decade of work on mobile paste applications ranging from a resort development program to a crown pillar stability remediation program.

\section{$2 \quad$ Three Sisters}

The Three Sisters site is located in the northern region of the northwest trending Cascade Coal Basin of Alberta on the eastern edge of Canmore, Alberta. Coal mines opened up in 1887 in support of the Trans Continental Railway. Since that time, 17 different coal operations have existed, the last having ceased operation in 1979. The mining method was 'room and pillar', and there is a history of ground subsidence in the area. As with many coal mines, the underground drifts rise and fall with the coal seam, and at times to surface.

Three Sisters Mountain Village Development received permission in the early 2000s to develop an 800 ha site in the area encompassing the old mine sites. They planned to build a housing community of 10,000 people, with a completion date of 2010 (it has been largely completed to date). The development includes wildlife corridors (60\% of 800 ha), two 18 hole golf courses, a wellness centre, a school, commercial buildings and residential condominium complexes. To date, between CDN $150 \mathrm{M}$ and CDN $200 \mathrm{M}$ in property has been sold. The current Three Sisters development can be seen in Figure 1.

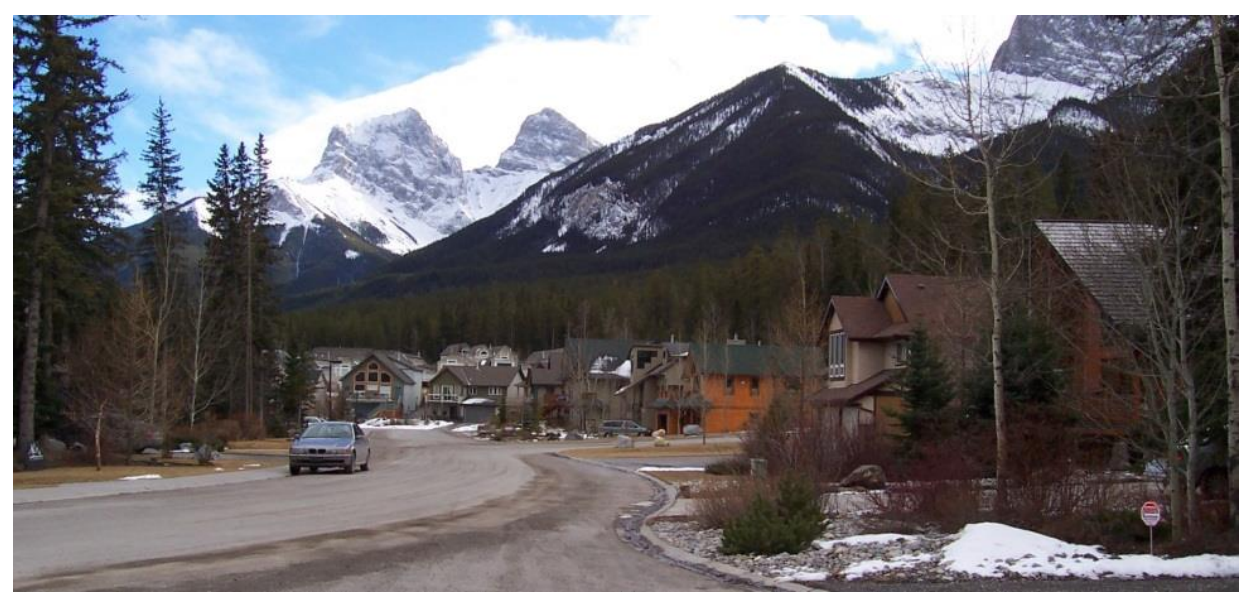

Figure 1 Three Sisters housing development 
One of the key factors influencing the Canmore Three Sisters development was a moratorium on Banff development. The Town of Banff has one of the premier ski resort facilities in the Rocky Mountains in Western Canada, but the local government decided that no additional residential development was to be allowed. With the demand for accommodation far exceeding supply, the unused land only one hour from Banff became an attractive prospect. However, there were several key concerns with utilising this land in an 'as is' condition. The main two being:

- Existing hazards to public and wildlife.

- Government regulations around proven mitigation practices.

Canmore is located in the foothills of the Rocky Mountains and, as such, there is a propensity by both locals and visitors to spend time in the outdoors. Hiking, skiing and mountain biking, amongst others, are all common activities in this part of the country. With so much of the area near Canmore being undermined, there was a hazard to people being on or near the old mine workings. The possibility of a sudden collapse was very real and in fact had already occurred in a number of places. This hazard also applied to wildlife, which uses the area to forage and as a corridor during seasonal movements.

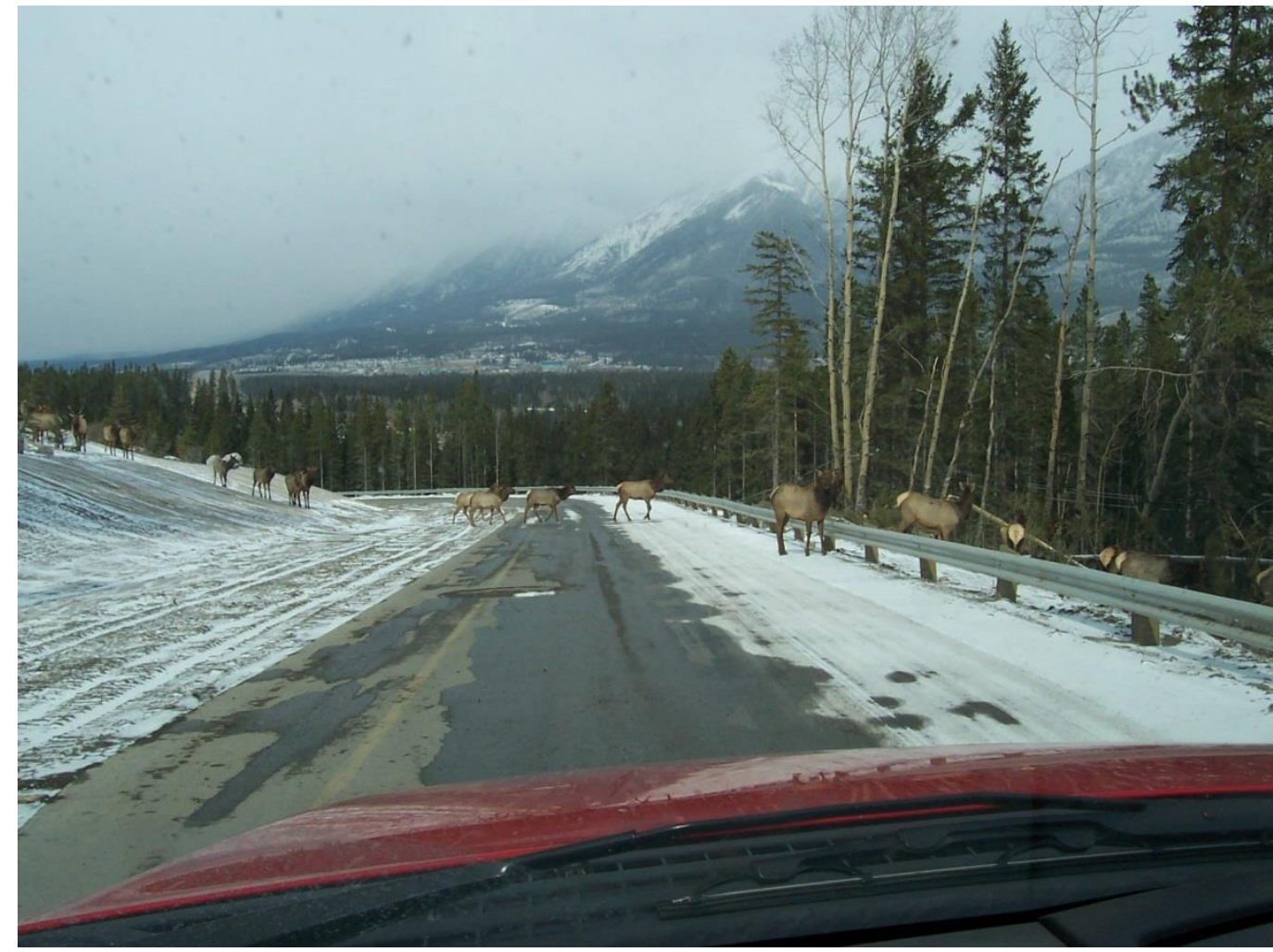

Figure 2 Elk crossing through the Three Sisters development area prior to construction

In addition, Alberta Provincial Regulation 114/97 (Government of Alberta 2001) requires any land developer to have their situation studied by a geotechnical engineer with experience in underground mine ground control and subsidence engineer, who prepares a report and recommendations. When these recommendations are carried out, the engineer certifies the results, which in turn are certified by an independent expert. Golder Associates Ltd. was commissioned by Three Sisters to study the site and make recommendations. Cemented paste technology was chosen as the practical and most economical solution, but as part of this assessment it was required to prove to the regulator that this solution was 'proven' and would provide the necessary geotechnical stability to the area. This was done via previous projects and test examples to demonstrate the effectiveness of paste backfill.

Once the approval was granted, the implementation phase began. Site conditions in the area, as can be seen in Figure 3, were of a highly mountainous, tree-lined area. 


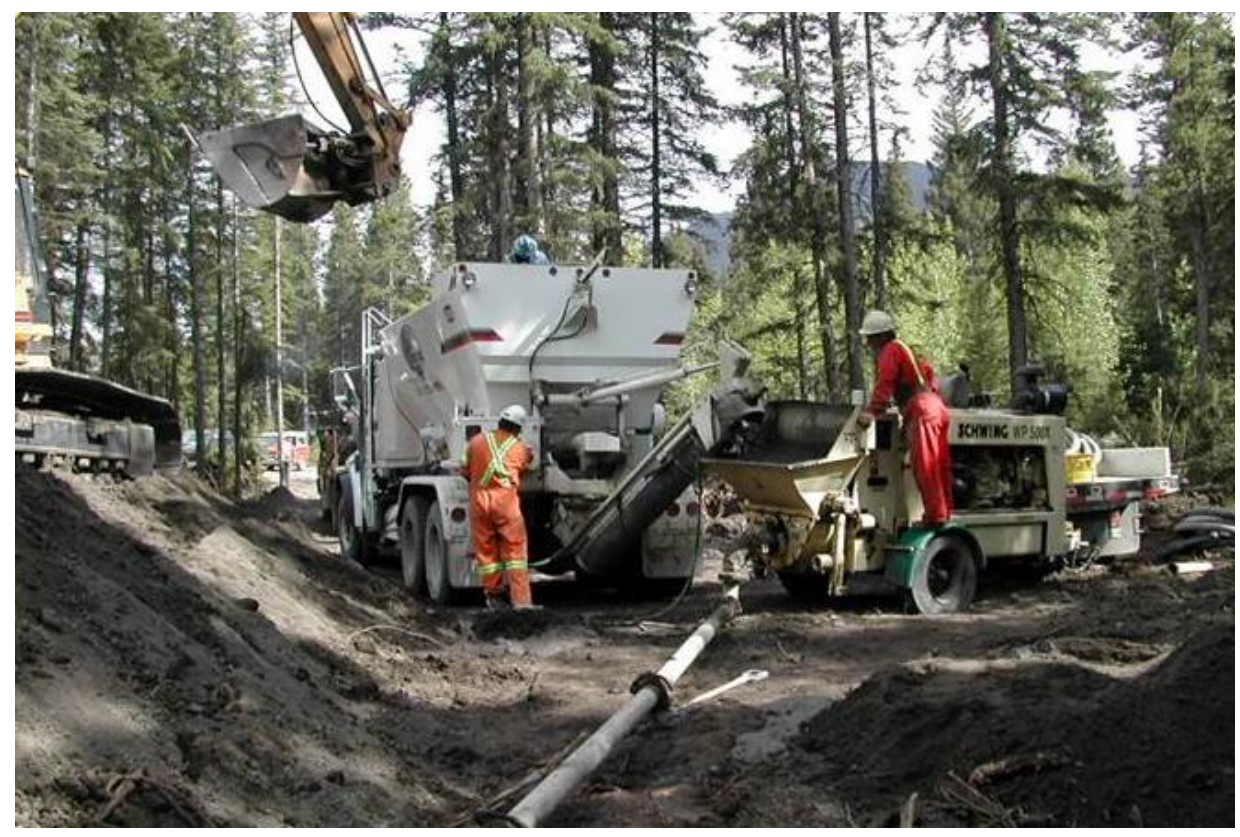

Figure 3 Set-up of mobile equipment and pipeline delivering paste backfill

With this kind of terrain and the breadth and depth of the backfill requirements, a fixed plant solution was not appropriate. Weather conditions in the mountainous area are also unpredictable, and can be treacherous in the winter, which meant that long pipelines were not going to be feasible. A new delivery method was required, and working with local contractors modified concrete equipment was developed that could deliver paste backfill from a mobile operation. Boreholes were mapped based on the geometry of the mine per the mine plans and on a maximum spacing of $15 \mathrm{~m}$ between holes. The depth of boreholes and the amount of material required per hole depended on the intended development. The undermined land was (and will continue to be) developed as anything from park land (low mitigation requirements) to multi-story resort hotels (high mitigation requirements).

Once they were drilled, a mobile set-up was initiated, which consisted of modified mixer truck, cement truck, water truck and concrete pump.

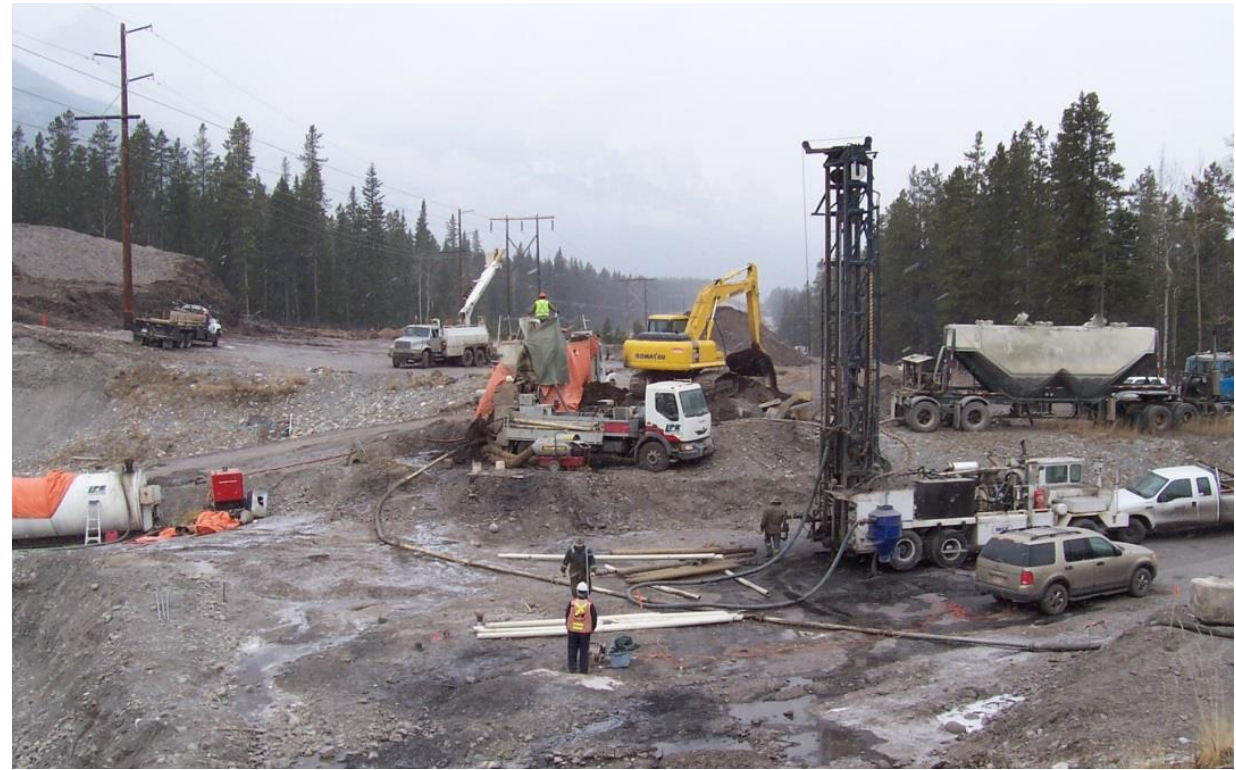

Figure 4 Typical set up with drilling happening at the same time and location as backfill operations 
Pipe was laid out to various holes within reasonable distances of the set-up, and pressure transmitters were installed to monitor pressures in the line as the holes were filled. Data was monitored and recorded on fill volume and pressures, and an extensive QC program was also conducted to ensure the strength of the material delivered underground. Areas to be backfilled were established on the model of the underground workings that was developed based on old mine plans and surveys done during the drilling program. The feed material was a challenge because no tailings were locally available. Fortunately, local borrow sources were located that would provide soil 'as is' with the appropriate particle-size distribution. This became one of the main environmental positives coming out of the project, as once an area of development was certified and construction on housing began, the material excavated for roads and basements became the feed material for the next phase of backfill. In this way, thousands of cubic metres of material were diverted from landfills. In total, at Three Sisters, 600 exploratory and injection holes have been drilled, with $24,000 \mathrm{~m}^{3}$ of paste injected to date.

\section{$3 \quad$ Giant Mine}

Giant Mine is a closed gold mine located in Yellowknife, Canada, that operated from 1948 until 1999, and then on a limited basis until July 2004, when mining operations ceased permanently. Due to Giant Mine's ore association with arsenopyrite, the process to extract gold generated high amounts of arsenic-rich gas as a by-product. As of 1951, several processes were put in place to capture most of this gas in the form of arsenic trioxide dust to be deposited in underground chambers that are isolated from other underground openings. It is believed that approximately 237,000 tonnes of soluble arsenic dust is currently stored underground in the arsenic stopes and chambers. Previous Golder project studies have also shown that the existing bulkheads and arsenic stope pillars (both crown pillars and pillars between stopes) needed to be reinforced to ensure they do not fail during the long-term closure of the underground workings.

The site is currently under care and maintenance by Aboriginal Affairs and Northern Development Canada (AANDC), which, in conjunction with the Government of the Northwest Territories, co-manages the Giant Mine Remediation Project. The site has long been an area of concern for the government and is a very complicated situation that exacerbates the difficulty of finding solutions. Close proximity to the city of Yellowknife (approximately $5 \mathrm{~km}$ ) and a local waterway, Baker Creek, which runs through the site, provide additional areas of concern. Another example of the complexity of the operation is the accuracy of the mine level plans, which in some cases contradict each other. Giant Mine, during production, had such competent rock that little was done in the way of support underground. There are few rock bolts, almost no screens, and little backfill. What this has meant over time is that things have moved and shifted in areas of the mine and, in particular, the crown pillars are becoming unstable.

In order to protect human health, public safety and the environment, an advanced remediation project is providing underground structural support to stabilise the site. This reinforcement was started in 2013, using cemented paste backfill. Golder Associates Ltd. determined that using existing tailings from the site and processing them into a paste backfill would enable the open voids to be filled. This minimises potential failure of the underground workings, especially for stopes that contain arsenic or are adjacent to such stopes. Without structural fill in the underground, previous Golder analysis showed that there could be a significant risk of crown pillar collapse in one part of the mine that could propagate and cause failure elsewhere. This would have environmental ramifications, especially for the stopes containing arsenic.

The original plan was to complete the first stage of paste backfill during the summer of 2013, but various delays caused the testing and backfill program to get underway in October 2013. At this far northern location, that meant long, cold days. Daylight hours were short and much work was conducted using artificial lighting platforms. 
Snow and wind, coupled with temperatures ranging from $-25^{\circ}$ to $-52^{\circ} \mathrm{C}\left(-13^{\circ}\right.$ to $-61^{\circ} \mathrm{F}$, made the project extremely challenging. With the complexity of the site, distance from the tailings deposit and the extremely small footprint available, a fixed paste plant was not feasible. Turning again to a mobile system, the modified mixer truck, cement silos, water tanks and boom pump truck were utilised to produce paste backfill.

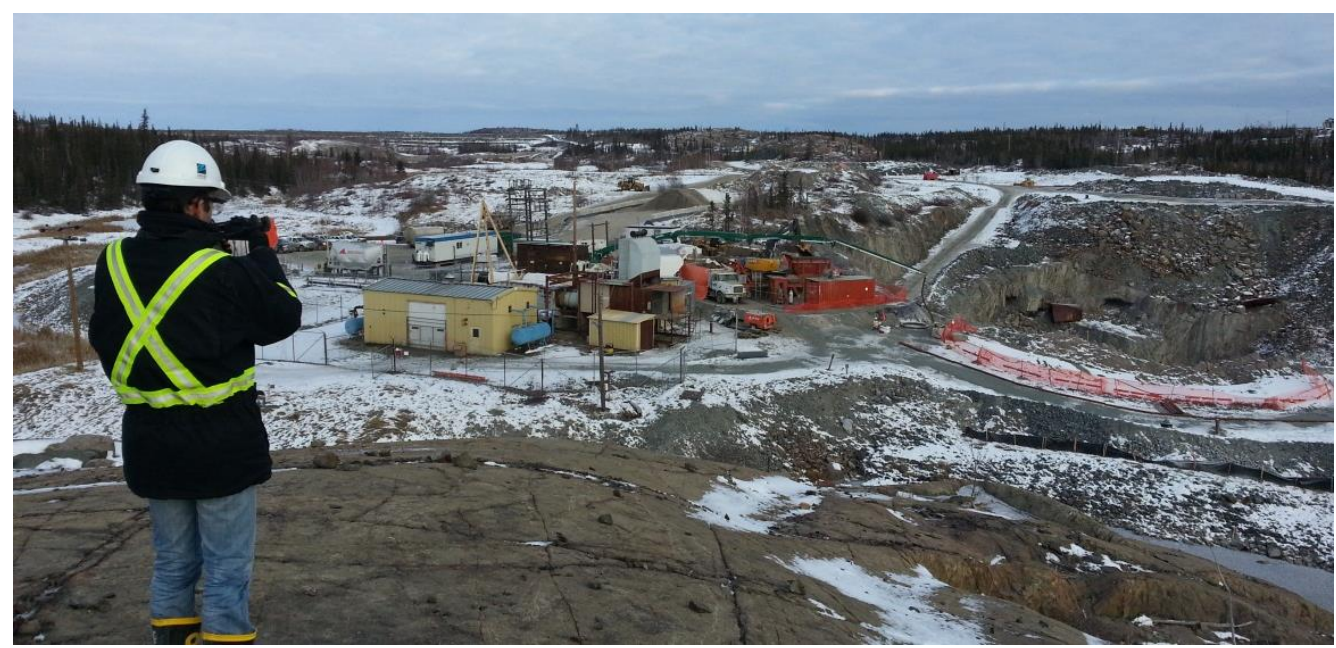

Figure 5 Set-up of the mobile backfill system in between the open pit and existing ventilation station on surface with Baker Creek running through the foreground

Producing paste backfill from a mobile system using frozen arsenic-laden tailings at these temperatures had not been done before, to our knowledge. An adaptive approach to deliver paste that met the specifications required in the permits and licensing was required. This included recording temperatures of feed materials and paste going into the ground as well as tracking via camera and cavity monitoring pour volumes within the stopes to guarantee tight filling to the back. An additional area of focus was around the water - there were limits on taking water from the polishing pond on site and, of course, the general concern with the handling of the arsenic tailings.

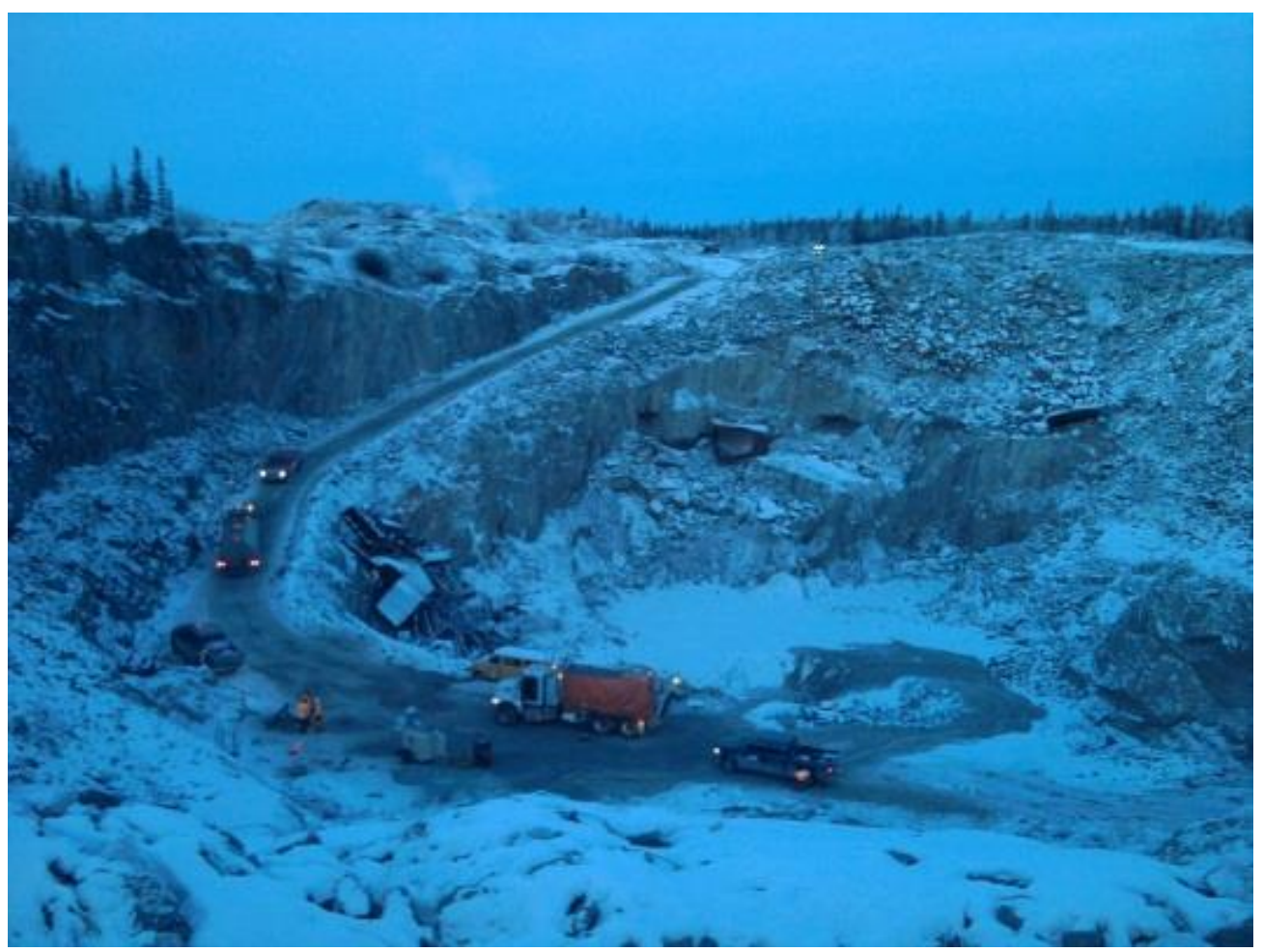

Figure 6 Gravity paste backfill pour in the open pit 


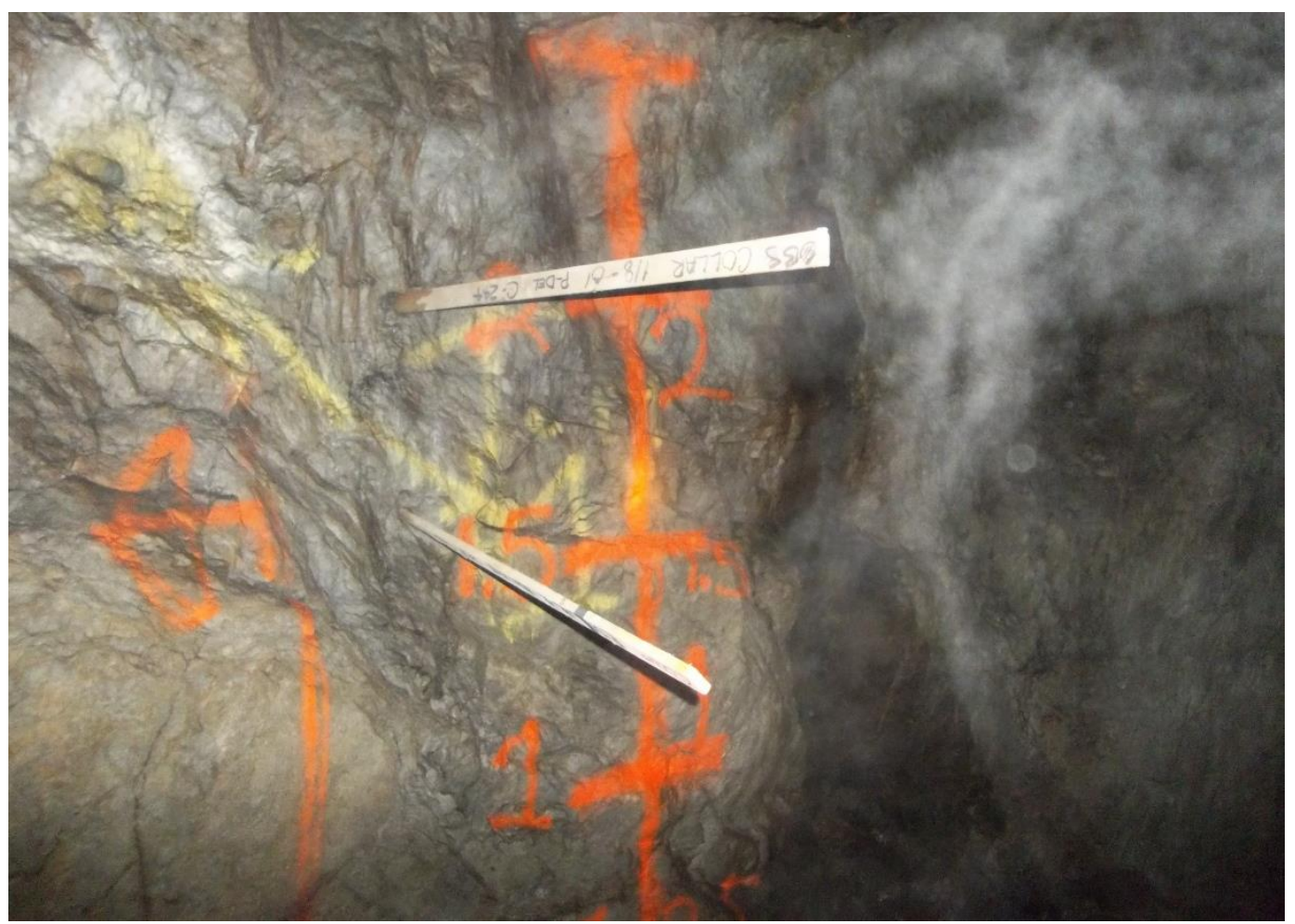

Figure 7 Markings to track fill progress in the underground stopes

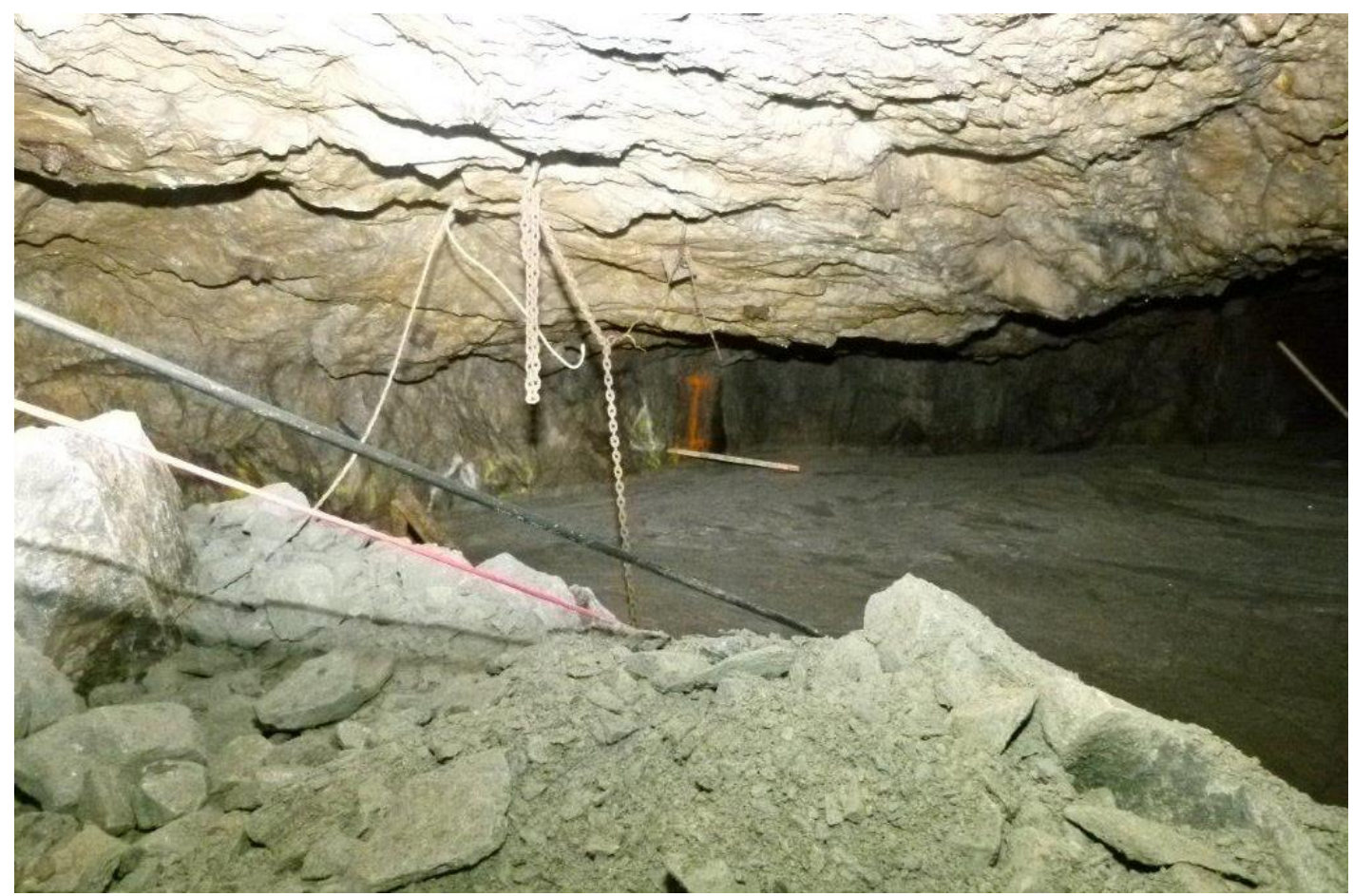

Figure 8 Paste measured against markings

Filling the designated voids while keeping other parts of the mine open and unhindered by paste called for ingenuity and flexibility with not only paste recipes, but also the drilling, monitoring and underground distribution system logistics and planning. Much of the underground was inaccessible, and mine plans were not complete; in some cases, limiting the flow of paste into unknown areas of the mine required multiple 'if-then-else' strategies during operation. Some of these scenarios included adjusting the recipe to lower slumps or higher binder contents and testing if the flow could be managed. 


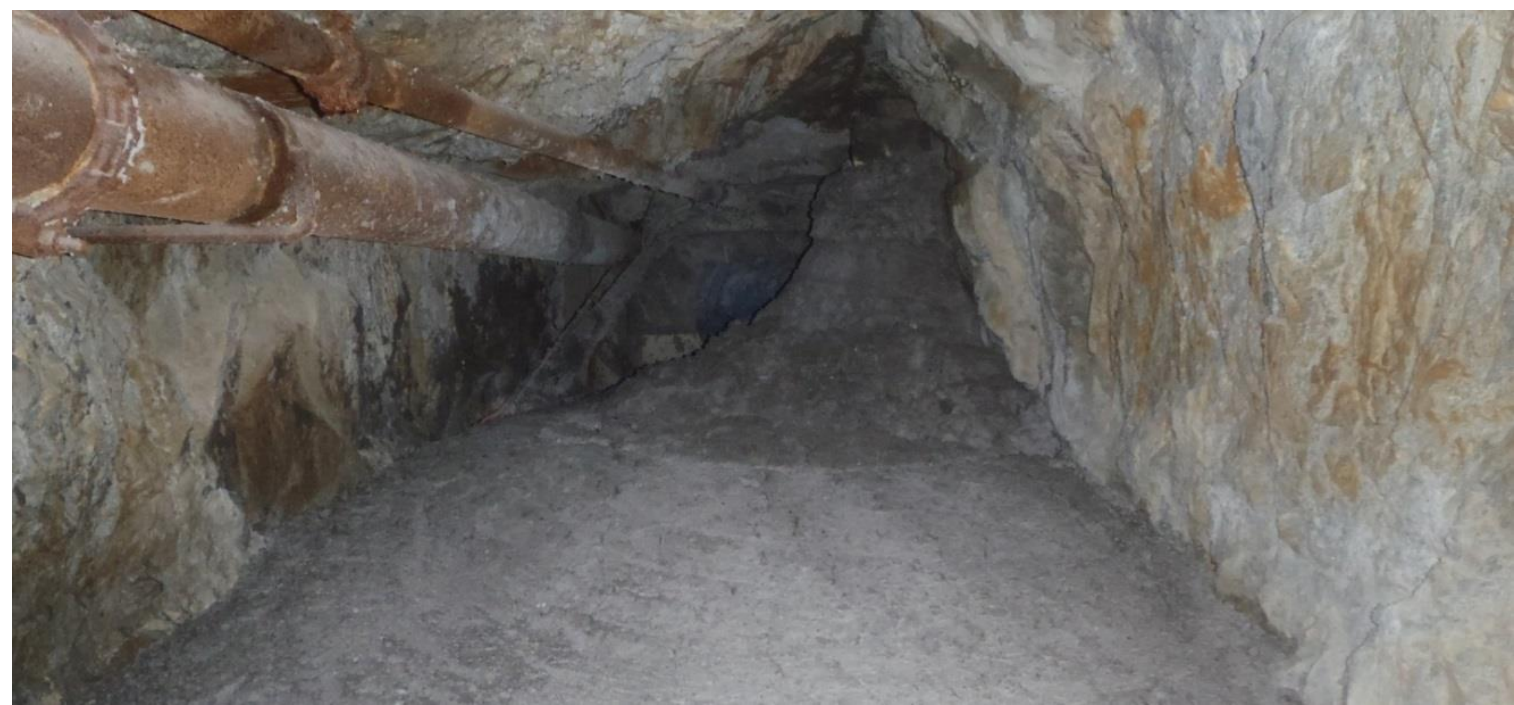

Figure 9 Remotely poured underground bulkhead made from paste backfill

Geotechnical investigations and process design studies along with laboratory testing programs were completed to analyse the tailings at Giant Mine for suitability as a feed material for paste backfill. In addition, quality assurance/quality control (QA/QC) services were provided to oversee, monitor, and test the backfill products for adherence to the design criteria. Notable achievements were:

- $11,000 \mathrm{~m}^{3}$ of paste backfill pumped underground in 2.5 months.

- Over 1,500 cylinders were cast for strength confirmation.

- Five different paste backfill recipes were utilised for stope specific pour requirements.

- Remote pumped paste backfill bulkheads were constructed to seal off drifts before bulk paste fill was poured.

- Surface backfill system ran in severe temperatures, including pouring paste backfill at $-40^{\circ} \mathrm{C}$.

- Diversion of arsenic tailings from surface to underground.

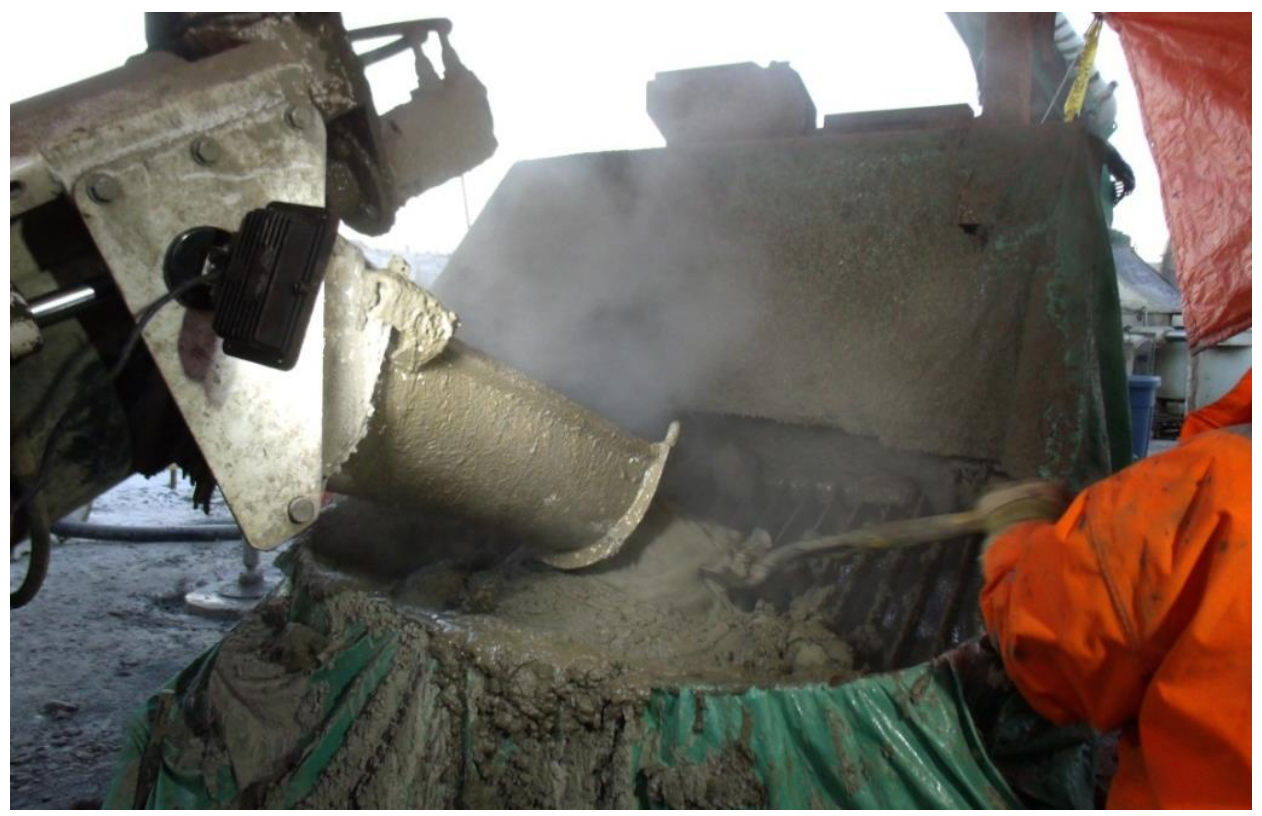

Figure 10 Paste backfill going into pump hopper at $-40^{\circ} \mathrm{C}$ 


\section{$4 \quad$ Conclusions}

In dealing with abandoned or orphaned mines, long-term stability is a key goal whether the intention is to promote urban development or simply address remediation and closure concerns. Mobile paste backfill systems are feasible alternatives to fixed plants and can provide owners with flexibility and adaptability to site conditions while still maintaining the quality and reproducibility of a traditional paste plant. The key is to understand the underground environment as well as the surface implications (e.g. set-up, moves, recipe development and infrastructure or material constraints) and to develop a specific plan to address these items in a timely and cost-effective manner. This is especially true if the owner is local, regional or federal governments who typically do not have the resources, technical or otherwise, to engage in these activities themselves.

\section{Acknowledgements}

The authors wish to express their gratitude to the team at Aboriginal Affairs and Northern Development Canada for their permission to publish this work.

\section{References}

Government of Alberta 2001, Alberta Regulation 114/97: Municipal Government Act - Canmore Undermining Review Regulation, Alberta Queen's Printer, Edmonton. 